\title{
Prevalence of Obstructive Sleep Apnea and Factors Affecting It among Old Age Population of Rural Area of Pakistan
}

\author{
Tayyab Mumtaz Khan, Manahil Jamil, Ali Imran Dhillon, Muhammad Junaid Umer, \\ Mian Muhammad Hassan Ahmed, Laraib Arsh, Somia Bibi, and Madeeha Mumtaz
}

\section{ABSTRACT}

\begin{abstract}
Although Obstructive sleep apnea is now recognized as one of the major public health problems because of the improvement in standards of life, however, with increasing its prevalence, it adversely affects the quality of life. So, our study was set to assess the prevalence of OSA and the factors that affect it. This may make new opportunities available by which we could bring a decline in OSA incidence after measuring its prevalence and identification of factors that affect it. This cross-sectional study was conducted in a nearby rural area of (THQ) Tehsil Headquarter Hospital, Phalia, Punjab for around three months from August 2020 to October 2020. Data was collected with the help of two questionnaires including a selfstructured proforma and STOP scale. People with age less than 51years and more than 60 years were excluded and only people with age above 50 years and below 61 years were included. Data analysis was accomplished with the help of SPSS version 25 and various tests including the Chi-square test, Independent Sample t-test, and One-Way ANOVA were applied to assess the study variables. Results of the study showed an overall high prevalence of OSA higher risk $(41.7 \%$ participants had a higher risk of development of OSA) Association, between OSA risk and age groups $(\mathrm{p}=0.001)$ and between OSA risk and Educational status $(\mathbf{0 . 0 0 0})$ was significant statistically, while it was not significant between OSA risk and gender $(p=0.394)$. The difference in score on the STOP scale was significant, across gender $(p=0.032)$, three age groups $(p=0.002)$, and four levels of education $(\mathrm{p}=\mathbf{0 . 0 0 0})$. Our study indicates an increased prevalence of higher risk for OSA development particularly among men, higher age, and lower education. So, proper planning is required to deal with the increasing prevalence of obstructive sleep apnea.
\end{abstract}

Keywords: Prevalence, Obstructive Sleep Apnea, Factors, Old Age, Population, Rural Area, Pakistan.

\section{INTRODUCTION}

Improvements in the healthcare system and standard of living have increased interest in the conditions that were given little value previously. Many of these conditions indirectly affect mortality rates [1]. Obstructive sleep apnea (OSA) is one of such conditions with significant adverse consequences and it is increasingly being recognized as a major source of public health concern in the last two to three decades [2]. It can be identified by recurring episodes of cessation (apnea) or reduction (hypopnea) in airflow during sleep caused by an obstruction in the upper airway [3]. These apnea and hypopnea events can be detrimental to health and can cause intermittent hypoxia, fragmented sleep, and exaggerated fluctuations in heart rhythm, blood pressure, and intrathoracic pressure [4]. Typical symptoms of OSA include
Published Online: January 29, 2021

ISSN: $2593-8339$

DOI: $10.24018 /$ ejmed.2021.3.1.679

Tayyab Mumtaz Khan*

Rawalpindi Medical University, Rawalpindi, Pakistan.

(e-mail: tayyab.mkhan98@gmail.com) Manahil Jamil

Rawalpindi Medical University, Rawalpindi, Pakistan.

Ali Imran Dhillon

Rawalpindi Medical University, Rawalpindi, Pakistan.

Muhammad Junaid Umer

Rawalpindi Medical University,

Rawalpindi, Pakistan.

Mian Muhammad Hassan Ahmed

Rawalpindi Medical University,

Rawalpindi, Pakistan.

Laraib Arsh

Rawalpindi Medical University,

Rawalpindi, Pakistan.

Somia Bibi

Rawalpindi Medical University,

Rawalpindi, Pakistan.

Madeeha Mumtaz

Lahore College for Women University, Pakistan.

*Corresponding Author

chronic loud snoring, excessive daytime sleepiness, and decreased cognitive functioning. Evidence suggests that obstructive sleep apnea may result in cardiovascular diseases, and impaired quality of life, and declined productivity of affected individuals [5], [6]. Early recognition and management can reverse severe consequences and may also bring favorable effects on cardiovascular health in the form of a reduction in the risk of cardiovascular diseases [7]. In the general population, OSA is associated with certain risk factors such as age, male gender, body mass index (BMI), family history, menopause, craniofacial abnormalities, metabolic syndrome, high blood pressure, and certain health risk behaviors such as cigarette smoking and alcohol [8]. Various studies have described an increased prevalence of OSA with advancing age, increased BMI, and male sex [9], [10]. A study in the literature reported that both the prevalence and severity of sleep apnea increase with age [11]. 
Similarly, another study also reports a two-fold greater prevalence of OSA in the elderly [12]. However, it has been observed that OSA presents with similar features in the elderly and young, and it remains frequently undiagnosed in the elderly because symptoms of snoring, nocturia, daytime sleepiness, fatigue, and cognitive dysfunction are attributed to other disorders or aging [13]. As at the old age population, OSA remains undiagnosed, because of symptoms that are common in other diseases of this age as well, we must pay attention towards the diagnosis of OSA in the old age population. According to our knowledge, various studies have been conducted internationally, depicting the prevalence of sleep apnea. However, in literature, nationally and locally, a few studies were found in which obstructive sleep apnea had been studied. So, in the presence of very few studies, our study aims to evaluate the prevalence of OSA and factors that affect it among the old age population of rural area of (THQ) Tehsil Headquarter Hospital Phalia, Punjab, Pakistan, and our study would be the first of its kind in our region using the STOP questionnaire to determine the prevalence of high risk for obstructive sleep apnea among old age population. If the results of our study show a higher prevalence of OSA among the old age population then authorities that are related to health must put interventions into action to bring down the prevalence of OSA to the lowest possible level, that would not only improve the quality of life among old age population but also would bring a decline in risk of cardiovascular disorders and other diseases of old age population.

\section{MATERIALS AND METHODS}

\section{A. Study Design and Study Population}

This descriptive cross-sectional study was conducted on old age patient population in a nearby rural area of (THQ) Tehsil Headquarter Hospital, Phalia, Punjab, for the duration of approximately 3 months from August 2020 to October 2020. 283 patients were recruited in the study based on study exclusion and inclusion criteria i.e., only those patients were enrolled in the study who had age more than 50 years and who were willing to participate with the exclusion of those who had age less than 51 years and were not willing to participate. Data collection was completed via two questionnaires including self-structured proforma and STOP scale for OSA, after an appropriate explanation of the objectives of the study, an informed consent was obtained from all enrolled participants. Then by interview of study population questionnaires were filled individually.

\section{B. Assessment of Characteristics of the Study Population and Educational Status}

A Self-structured proforma was created to get information about the demographic components including age, gender, and educational status. Based on age patients were grouped into three groups including Group 1 (those with age from 51 to 55 years). Group 2 (those from 56 to 60 years) and Group 3 (those with age 61 years and above). Likewise, the study population's educational status was also noted. Four educational levels were used including illiterate, Primary, Under Matric, Matric, and above Matric.

\section{Assessment of Obstructive Sleep Apnea}

STOP Questionnaire for Obstructive Sleep Apnea (OSA) was used for the evaluation of the risk of OSA, which has also been used internationally [17]. The complete form of this questionnaire is STOP-BANG, however, we used only the STOP part of it. STOP consisted of four questions $(S=$ do you Snore loudly? $\mathrm{T}=$ do you often feel Tiredness or daytime sleepiness? $\mathrm{O}=$ have you Observed stop of breathing during sleep? and $\mathrm{P}=$ have you or are you being treated for high Blood Pressure?). The answer to each of these questions could be $\mathrm{YES}=1$ or $\mathrm{NO}=0$. So, the total score could range from 0 to 4 . Based on the score of yes or no, participants were divided into two categories High risk and low risk for the development of OSA. Patients who had answered yes to two or more questions were considered as high risk and patients who had answered yes to only one or none were considered as low risk.

\section{Data Analysis}

A descriptive data analysis was carried out through SPSS version 25 of the study variables. A pilot study was conducted on 38 participants, to check the reliability of the STOP Questionnaire for Obstructive Sleep Apnea (OSA). Cronbach alpha value was calculated, and it was 0.781 indicating high reliability of the STOP Questionnaire for OSA. Chi-square analysis was done to assess the relationship between OSA risk and factors including gender, various age groups, and educational status. The difference in STOP score across the gender was assessed by applying an Independent sample ttest. Difference STOP score among study population based on their age and educational status was checked by One-Way ANOVA test. The value of $\mathrm{p}$ less than 0.05 was considered statistically significant.

\section{RESULTS}

For a total of 283 Participants, who were enrolled in our study, the mean age was 58.66 years with a standard deviation (SD) of \pm 5.80 years while the mean score for the study population on the STOP scale for obstructive sleep apnea (OSA) was 1.98 with SD of \pm 1.36 .

Table I shows that $118(41.7 \%)$ participants had a higher risk of development of OSA whereas 165 (58.3\%) had a lower risk for OSA development. The risk was more prevalent among men, older, and illiterate participants in comparison to women, relatively younger and relatively educated participants which means that gender, age, and educational status are important are contributing factors towards the increase in the risk of Obstructive Sleep Apnea. Moreover, it also shows the parameters of population along with their cross-tabulation with study variable and chi-square analysis for assessment of the relationship between OSA and gender $(\mathrm{p}=0.394)$, between OSA and age $(\mathrm{p}=0.001)$, and between OSA and educational status $(\mathrm{p}=0.000)$.

Table II indicates gender-based variation in mean score on STOP scale for OSA (obstructive Sleep Apnea) along with results of independent sample t-test and this difference was statistically significant ( $p=0.032$ ). Men had more mean score as compared to women which means that they had a higher risk for OSA. 
TABLE I: POPULATION PARAMETERS ALONG WITH THEIR CROSSTABULATION WITH STUDY VARIABLES AND CHI-SQUARE ANALYSIS

\begin{tabular}{|c|c|c|c|c|}
\hline \multicolumn{5}{|c|}{ Cross-Tabulation and chi-square analysis } \\
\hline \multirow{2}{*}{\multicolumn{2}{|c|}{ Parameter }} & \multicolumn{2}{|c|}{ Obstructive Sleep Apnea Risk } & \multirow{2}{*}{$\begin{array}{c}\text { Chi- } \\
\text { Square } \\
\text { Analysis }\end{array}$} \\
\hline & & Higher Risk & Lower Risk & \\
\hline \multicolumn{2}{|c|}{ Total $=283$} & $118(41.7 \%)$ & $\begin{array}{c}165 \\
(58.3 \%) \\
\end{array}$ & p-value \\
\hline \multirow{2}{*}{ Gender } & $\begin{array}{l}\text { Male } \\
\mathrm{n}=114\end{array}$ & $51(44.73 \%)$ & $\begin{array}{c}63 \\
(55.26 \%)\end{array}$ & \multirow{2}{*}{0.394} \\
\hline & $\begin{array}{c}\text { Female } \\
n=169\end{array}$ & $67(39.65 \%)$ & $\begin{array}{c}102 \\
(60.35 \%)\end{array}$ & \\
\hline \multirow{3}{*}{$\begin{array}{c}\text { Age } \\
\text { Groups }\end{array}$} & $\begin{array}{c}\text { Group } 1 \\
n=107\end{array}$ & $32(29.90 \%)$ & $\begin{array}{c}75 \\
(70.10 \%)\end{array}$ & \multirow{3}{*}{0.001} \\
\hline & $\begin{array}{c}\text { Group } 2 \\
\mathrm{n}=90\end{array}$ & $37(41.11 \%)$ & $\begin{array}{c}53 \\
(58.90 \%)\end{array}$ & \\
\hline & $\begin{array}{c}\text { Group } 3 \\
n=86\end{array}$ & $49(56.97 \%)$ & $\begin{array}{c}37 \\
(43.13 \%)\end{array}$ & \\
\hline \multirow{5}{*}{$\begin{array}{c}\text { Educational } \\
\text { Status }\end{array}$} & $\begin{array}{c}\text { Illiterate } \\
\mathrm{n}=79\end{array}$ & $43(54.43 \%)$ & $\begin{array}{c}36 \\
(45.56 \%)\end{array}$ & \multirow{5}{*}{0.000} \\
\hline & $\begin{array}{c}\text { Primary } \\
n=78\end{array}$ & $38(48.71 \%)$ & $\begin{array}{c}40 \\
(51.29 \%)\end{array}$ & \\
\hline & $\begin{array}{c}\text { Under } \\
\text { Matric } \\
n=62\end{array}$ & $23(37.10 \%)$ & $\begin{array}{c}39 \\
(62.90 \%)\end{array}$ & \\
\hline & $\begin{array}{l}\text { Matric } \\
\text { and }\end{array}$ & 14 & 50 & \\
\hline & $\begin{array}{c}\text { Above } \\
n=64\end{array}$ & $(21.87 \%)$ & $(78.13 \%)$ & \\
\hline
\end{tabular}

TABLE II: DIFFERENCE IN STOP SCALE SCORE BASED ON GENDER AND INDEPENDENT SAMPLE T-TEST ANALYSIS

\begin{tabular}{cccc}
\multicolumn{3}{c}{ INDEPENDENT SAMPLE T-TEST ANALYSIS } \\
\hline \multirow{2}{*}{ Parameter } & STOP Scale Score & $\begin{array}{c}\text { Independent Sample } \\
\text { t-test }\end{array}$ \\
\cline { 3 - 4 } & Male & Mean $( \pm$ SD) & p-value \\
\hline \multirow{2}{*}{ Gender } & Female & $\begin{array}{c}1.20( \pm 1.45) \\
\text { Sem }\end{array}$ & 0.032 \\
\hline
\end{tabular}

Table III summarizes the difference in mean score on the STOP scale for OSA (obstructive Sleep Apnea) among different groups of participants based on their age and educational status. STOP mean score was highest among older and illiterate participants and it was lowest among relatively younger and more educated participants. A higher score means a higher risk of OSA. This difference was also statistically significant among participants, of various age groups $(\mathrm{p}=0.002)$ and of various educational status levels $(\mathrm{p}=0.000)$.

Our study result shows an overall high prevalence of risk of obstructive sleep apnea among the old age population and also shows that gender, age, and educational status are very important factors that impact the risk of OSA.

TABLE III: DifFERENCE IN STOP SCALE SCORE ON THE BASIS OF AGE GROUPS AND EDUCATIONAL STATUS ALONG WITH ONE-WAY ANOVA

\begin{tabular}{cccc}
\multicolumn{4}{c}{ ANALYSIS } \\
\hline \multirow{2}{*}{ Parameter } & $\begin{array}{c}\text { STOP Scale } \\
\text { Score }\end{array}$ & $\begin{array}{c}\text { One Way } \\
\text { ANOVA }\end{array}$ \\
\cline { 2 - 4 } & Group 1 & Mean \pm S. D & p-value \\
\hline \multirow{3}{*}{ Age groups } & Group 2 & $2.67( \pm 1.35)$ & \\
& Group 3 & $2.36( \pm 1.35)$ & 0.002 \\
& Illiterate & $2.35( \pm 1.31)$ & \\
Educational & Primary & $2.21( \pm 1.38)$ & \\
Status & Under Matric & $1.88( \pm 1.36)$ & 0.000 \\
& Matric and & $1.35( \pm 1.23)$ & \\
& Above &
\end{tabular}

\section{IV.DISCUSSION}

Obstructive sleep apnea is a major health issue, and its prevalence is thought to be increasing with the aging of the population. The study provides valuable information regarding the prevalence of high risk and low risk of obstructive sleep apnea along with the effect of factors like gender, aging, and educational status. among the old population of rural areas of (THQ) Tehsil Headquarter Hospital Phalia, Punjab, Pakistan. Our current study shows an overall high prevalence of individuals who had a higher risk of development of OSA at the old age population of Pakistan. $118(41.7 \%)$ participants had a higher risk of development of OSA whereas 165 (58.3\%) had a lower risk for OSA development. After observing the prevalence of high-risk individuals in our current population, we noticed that male participants had a higher score on the STOP scale, and more men had a higher risk of OSA as compared to women who had a lower score on the STOP scale and lesser number of women had a higher risk of OSA. Although the association between gender and OSA was not significant statistically $(\mathrm{p}=0.394)$ and this was checked by the Chi-square test. The difference of mean score between men and women was not significant statistically $(\mathrm{p}=0.032)$ and it was assessed by Independent Sample t-test. Different studies that were conducted in the United States of America and Saudi Arabia have been reported similar findings, that males had a higher risk of development of OSA [14], [15]. In the next step of data analysis, we noted that with an increase in age, the risk of OSA goes up. We also found that the association between age and OSA risk was significant statistically $(\mathrm{p}=0.001)$ and again Chi-square was used to assess this association. Then One-Way ANOVA test was applied to evaluate whether the difference in STOP score is significant or not and we noticed that differences across the three age groups were significant statistically $(\mathrm{p}=0.002)$. Internationally, various studies had also shown similar results that with the increase in age, the risk of OSA rises [16]-[18]. At end of the data analysis, we found that the educational status was also important in the determination of the risk of OSA. After applying the Chisquare test, educational status was also found associated significantly $(\mathrm{p}=\mathrm{P}=0.000)$, with an increase in the risk of OSA. The difference of score on the STOP scale, across the four levels, was also significant $(p=0001)$. This finding is consistent with the results of a study that was conducted in Iran that lower education is associated higher risk of Obstructive sleep apnea [17]. Even though our study has limitations due to its cross-sectional layout, however, our current study is one of those few studies that have brought Obstructive sleep apnea prevalence and factors that affect it, into the spotlight. The current study has shown a high prevalence among the old population particularly, among men. Participants with higher age, and participants with lower educational levels. Although, age and gender are nonmodifiable factors, nevertheless, educational status could be improved, through which we would be able to bring a decline in risk of OSA in the old population. And in the case of gender and aging, which are inevitable factors, we could still reduce the risk of OSA in the old men population by the implementation of proper measures against those triggering factors and diseases that are risk factors of OSA in men and aged population like obesity. So, health development must apply serious and proper interventions for the reduction of risk of OSA, that would lead to a not only improvement in the quality of lives and productivity of participants, but it would also lead to a decline in the risk of diseases for which OSA is 
considered as risk factor like cardiovascular system-related disorders.

\section{CONCLUSION}

In short, our study shows an overall high prevalence of individuals with a high risk for Obstructive Sleep Apnea among the old age population of rural areas of Pakistan. Moreover, the high-risk prevalence was more prevalent among men, participants with higher age, and participants with lower educational level as compared to women, participants with lower age, and participants with a higher educational level. So, implementation of proper interventions is required to control the increasing risk of Obstructive Sleep Apnea, because by a reduction in OSA incidence we could not only improve the overall quality of lives and productivity of people but also, we could bring down the risk of serious diseases like cardiovascular systems.

\section{ACKNOWLEDGMENT}

We (Tayyab Mumtaz Khan, the principal author and all coauthors) thank all respected individuals, who participated in this research.

\section{REFERENCES}

[1] Sultan N, Ajmal M, Imad-ud-din Saqib AM, Iqbal M, Mateen F, Naseem S, Siddiqui M, Iftikhar A. Obstructive Sleep Apnoea in Pakistan: A Single Tertiary Care Center Experience. Cureus. 2019 Dec;11(12).

[2] Sogebi OA, Ogunwale A. Risk factors of obstructive sleep apnea among nigerian outpatients. Brazilian journal of otorhinolaryngology. 2012 Dec;78(6):27-33.

[3] Laratta CR, Ayas NT, Povitz M, Pendharkar SR. Diagnosis and treatment of obstructive sleep apnea in adults. Cmaj. 2017 Dec 4;189(48):E1481-8.

[4] Peppard PE, Young T, Barnet JH, Palta M, Hagen EW, Hla KM. Increased prevalence of sleep-disordered breathing in adults. American journal of epidemiology. 2013 May 1;177(9):1006-14.

[5] Shochat T, Pillar G. Sleep apnoea in the older adult. Drugs \& aging. 2003 Jul 1;20(8):551-60.

[6] Banno K, Kryger MH. Sleep apnea: clinical investigations in humans. Sleep medicine. 2007 Jun 1;8(4):400-26.

[7] Marin JM, Carrizo SJ, Vicente E, Agusti AG. Long-term cardiovascular outcomes in men with obstructive sleep apnoeahypopnoea with or without treatment with continuous positive airway pressure: an observational study. The Lancet. 2005 Mar 19;365(9464):1046-53.

[8] Punjabi NM. The epidemiology of adult obstructive sleep apnea. Proceedings of the American Thoracic Society. 2008 Feb 15;5(2):13643.

[9] Senaratna CV, Perret JL, Lodge CJ, Lowe AJ, Campbell BE, Matheson MC, Hamilton GS, Dharmage SC. Prevalence of obstructive sleep apnea in the general population: a systematic review. Sleep medicine reviews. 2017 Aug 1;34:70-81.

[10] Ralls FM, Grigg-Damberger M. Roles of gender, age, race/ethnicity, and residential socioeconomics in obstructive sleep apnea syndromes. Current opinion in pulmonary medicine. 2012 Nov 1;18(6):568-73.

[11] Hongyo K, Ito N, Yamamoto K, Yasunobe Y, Takeda M, Oguro R, Takami Y, Takeya Y, Sugimoto K, Rakugi H. Factors associated with the severity of obstructive sleep apnea in older adults. Geriatrics \& Gerontology International. 2017 Apr;17(4):614-21.

[12] Glasser M, Bailey N, McMillan A, Goff E, Morrell MJ. Sleep apnoea in older people. Breathe. 2011 Mar 1;7(3):248-56.

[13] Norman D, Loredo JS. Obstructive sleep apnea in older adults. Clinics in geriatric medicine. $2008 \mathrm{Feb}$ 1;24(1):151-65.

[14] Lin CM, Davidson TM, Ancoli-Israel S. Gender differences in obstructive sleep apnea and treatment implications. Sleep medicine reviews. 2008 Dec 1;12(6):481-96.
[15] Wali SO, Abalkhail B, Krayem A. Prevalence and risk factors of obstructive sleep apnea syndrome in a Saudi Arabian population. Annals of thoracic medicine. 2017 Apr;12(2):88.

[16] Bixler EO, Vgontzas AN, Ten Have T, Tyson K, Kales A. Effects of age on sleep apnea in men: I. Prevalence and severity. American journal of respiratory and critical care medicine. 1998 Jan 1;157(1):144-8

[17] Foroughi M, Malekmohammad M, Sharafkhaneh A, Emami H, Adimi $\mathrm{P}$, Khoundabi B. Prevalence of obstructive sleep apnea in a high-risk population using the stop-bang questionnaire in Tehran, Iran. Tanaffos. 2017; 16(3):217.

[18] Durán J, Esnaola S, Rubio R, Iztueta Á. Obstructive sleep apneahypopnea and related clinical features in a population-based sample of subjects aged 30 to $70 \mathrm{yr}$. American journal of respiratory and critical care medicine. 2001 Mar 1;163(3):685-9.

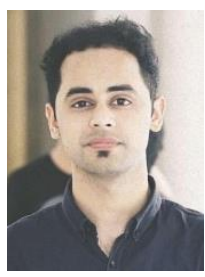

Tayyab Mumtaz Khan

Place of Birth: Lahore, Pakistan.

Date of Birth: $23^{\text {rd }}$ March 1996.

Educational Background: Final year MBBS student at

Rawalpindi Medical University Rawalpindi, Pakistan.

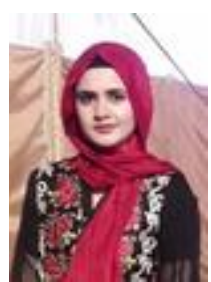

Manahil Jamil

Place of Birth: Vehari, Pakistan.

Date of Birth: 30 ${ }^{\text {th }}$ January 1997.

Educational Background: Final year MBBS student at

Rawalpindi Medical University Rawalpindi, Pakistan. 